\title{
Throughput Analysis for Non-Orthogonal Multiple Access (NOMA)-Based 5G Networks
}

\author{
Osama M.S. Abuajwa, Chee Keong Tan, Ching Kwang Lee
}

\begin{abstract}
Non-Orthogonal Multiple Access (NOMA) scheme is one of the emerging radio access techniques to enhance the system performance for $5 G$ networks. The powerdomain NOMA is one of the basic NOMA schemes that perform superposition coding (SC) at the transmitter and successive interference cancellation (SIC) at the receiver. Power Allocation (PA) plays a significant role in attaining successful SIC and high system throughput. This work is focusing on power allocation to maximize the throughput for NOMA-based $5 G$ network. The objective functions, algorithms, constraints and limitations of the system design in power allocation techniques for NOMA-based $5 G$ networks in terms of throughput analysis are extensively investigated and reported.
\end{abstract}

Keywords- Power Allocation (PA), Non-Orthogonal Multiple Access (NOMA), Orthogonal Multiple Access (OMA), Successive Interference Cancellation (SIC).

\section{INTRODUCTION}

NOMA scheme is envisioned as an emerging radio access technique to achieve high bit-rate and capacity for $5 \mathrm{G}$ networks. The ever-increasing demand of capacity by users have generated interest of researchers to seek alternative scheme to the existing OMA. The bandwidth resources allocation in OMA technique offered a low spectral efficiency under poor channel condition. Conversely, the NOMA scheme tends to allocate bandwidth for users regardless of their channel condition.

This is a significant improvement of the spectral efficiency over OMA [1].NOMA can provide high capacity and enhance spectral efficiency. However, there are many of challenges incorporating NOMA scheme in $5 \mathrm{G}$ networks due to various following reasons. Amongst them, the user pairing complexity and the requirements of channel state information (CSI) are the most standard issues. Moreover, the complexity of utilizing successive interference cancellation (SIC) techniques is also a major consideration.

The dominant NOMA solutions in 5G are classified into power-domain NOMA, code- domain NOMA, pattern division multiplexing access (PDMA), spatial division multiple access (SDMA), interleave multiple access, and bit division multiplexing [2].
This paper is focusing on the power- domain NOMA that utilizes power allocation (PA) techniques to enable users to share the same resources in time or frequency domains. The resource allocation and the PA schemes will be studied in detail to address various issues related to throughput maximization in NOMA-based 5G networks.

The paper is organized as follows. Section II discusses the basic concepts of NOMA system. The resource allocation techniques, as well as the problem formulation, algorithms and system designs, are described in Section III. The different PA algorithms are presented in Section IV. Section V, compare between the algorithms of waterfilling-Proportional Fairness (WF-PF) and Water -filling combined with NOMA-Orthogonal signaling (NOMAOS-WF) to analysis throughput performance. Moreover, the potential number of users that can be multiplexed on the same subcarrier is analyzed in the same section. Concluding remarks of this work are given in Section VI.

\section{BASIC CONCEPT OF NOMA}

A NOMA-based 5G system consists of multiple users sharing the same subcarrier served by a base station (BS).The users will be multiplexed on the same frequency using different level of transmit power, as shown in Figure 1 .This setup can also applied for code or time domain.

For illustration, Fig. 2 shows a downlink NOMA system consisting of two users.

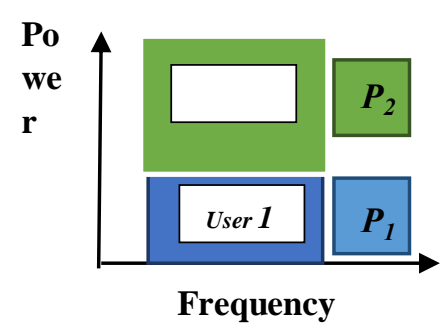

Figure 1 The transmit power levels in the NOMA scheme 


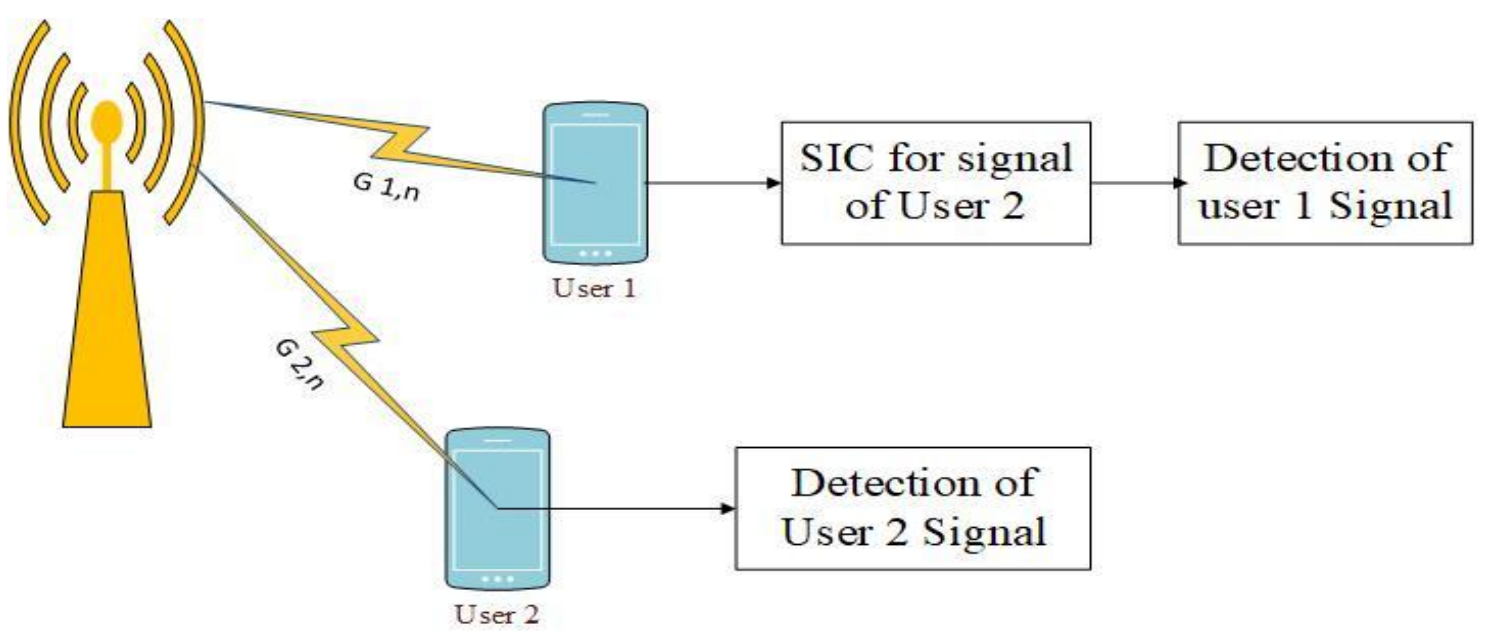

Fig. 2 Basic concept of NOMA scheme

The two multiplexed users receive a superimposed mixture of messages that are sent from the BS on the same subcarrier with a different level of transmitting power. This signal requires digital signal processing techniques to separate the mixed messages to ensure successful reception for each user. The NOMA system serves $U$ number of users with a total bandwidth $W_{T}$ with $N_{s c}$ number of subcarriers. In addition, the NOMA system employs the SIC to ensure interference cancellation between the two multiplexed users on the same subcarrier. The BS transmits the signal $X_{u, n}$ to the $u_{t h}$ user $(u \in\{1,2 \ldots U\})$ on the $n_{t h}$ subcarrier $(n \in\{1,2$ $\left.\ldots . ., N_{s c}\right\}$ ) using a transmission power $P_{u, n}$. The received signal $Y_{u}$ of the $u_{t h}$ user on the $n_{t h}$ subcarrier is given by [3] .

$$
Y_{u}=\sum_{i=1}^{U} \sqrt{P_{i, n}} G_{i, n} X_{i, n}+N_{i}
$$

Where $G_{i, n}$ is the channel gain between the BS and the $i_{t h}$ users multiplexed on the $n_{t h}$ subcarriers, while $N_{i}$ is the white additive Gaussian noise.

In the NOMA-based system, both multiplexed users will receive a combined signal for both users. Based on the NOMA concepts, SIC is applied on the multiplexed users who receive a stronger signal. The transmitted signal is a linear combination of the two messages for multiplexed users where SIC is applied at the receiver side [3].

As illustrated in Fig. 2 , the transmitted signals carry the intended massage to the both users are multiplexed on the same frequency. In this example, User 1 is assumed to experience better channel condition than that of User 2 . Thus, User 1 will perform SIC, which firstly decodes the message of User 2. Subsequently, User 1 cancels it from the received signal and decodes its intended message [3]. On the other hand, User 2 will consider the signal of User 1 as noise and decodes the intended message from the received signal. The achievable throughput for NOMA-based system can be expressed as given below.

$$
\begin{aligned}
& \mathrm{R}_{\text {User } 1}=B_{s c} \sum_{\substack{\mathrm{n}=1 \\
\mathrm{~N}_{\mathrm{sc}}}}^{\mathrm{N}_{\mathrm{sc}}} \log _{2}\left(1+\gamma_{1, \mathrm{n}}\right) \\
& \mathrm{R}_{\text {User } 2}=B_{s c} \sum_{\mathrm{n}=1} \log _{2}\left(1+\gamma_{2, \mathrm{n}}\right)
\end{aligned}
$$

where the subcarrier bandwidth is $B_{S C}=W_{T} / N_{S C}$ and $\gamma_{1, n}, \gamma_{2, n}$ is the signal to interference plus noise ratio $($ SINR) for user 1 and users 2 respectively. According to (2) and (3), the transmit powers $P_{1, n}$ and $P_{2, n}$ play a vital role on the throughput.

The power allocation problem in power-domain NOMA can be formulated to ensure the optimal solution in providing the maximum user's throughput subject to the maximum transmit power $P_{\text {total }}$. According to [1], NOMA system experiences encounter substantial cochannel interference that the user with the worst channel condition suffers from a low data rate due to its inability of removing the other user's interference.

This challenge can be solved by deploying the Interference cancellation techniques such as SIC or Interference Rejection Combining (IRC).This is one of the significant advantages of NOMA that enable efficient use of bandwidth resources over OMA [4]. In detail, the power levels for downlink or uplink of NOMA-based system can be manipulated to improve the performance of the overall throughput and capacity.

\section{POWER ALLOCATION FOR NOMA- BASED SYSTEMS}

In the PA NOMA schemes, the channel gain information is utilized to allocate the transmission power according to conventional PA techniques such as waterfilling, Fractional Transmit Power Allocation (FTPA), Fixed Power Allocation (FPA) and the Full Search Power Allocation (FSPA) [3]. These PA schemes allocate different power levels to different users based on their channel conditions.

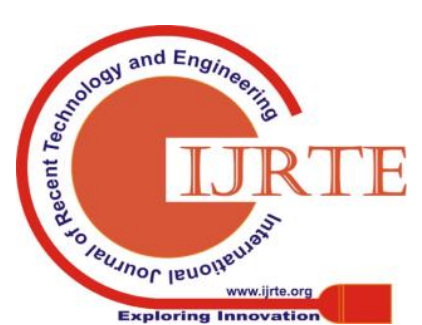


In NOMA-based networks, the users with the weak channel conditions get more allocated power to enable the user to decode its signal while the users with the stronger channel condition will be able to decode its signal too. This PA scheme works effectively in NOMA system because both users can access the allocated bandwidth regardless of the channel condition, unlike the conventional OMA.

This section investigates various PA algorithms together with their objective functions, problem formulation, algorithms constraints or limits and other considerations. The summary of the investigation is tabulated in Table 1 in the Appendix. Furthermore, we also analyze the PA in NOMA system for $5 \mathrm{G}$ networks in term of the throughput maximization.

The maximization will depend on the problem type such as whether it is convex or, non-convex, linear or nonlinear and how to transform into a solvable problem. The standard criteria of the current work using the same constraints such as transmit power, outage probability, QoS, data rate, energy harvesting and interference between PU and SU are highlighted in Error! Reference source not found.

\section{REVIEW OF POWER ALLOCATION FOR NOMA-BASED SYSTEM}

The throughput performance enhancement in NOMAbased system depends on many influences such as the statistical or dynamical CSI, the power distribution among the sub bands, the number of multiplexed users and the antenna patterns [2], [5] , [6], [7]. In addition, the joint detection scheme proposed in [8] focuses more on the distance between the user and BS, where the proposed scheme employs the distance as one of the techniques to form user pairing. In [9], the iterative water-filling-based PA considers the channel gains as a primary indicator for user pairing techniques. Moreover, the proportional fairness $(\mathrm{PF})$ in [9] performs singular value decomposition (SVD) which ranks the users based on their channel gains thereby increasing the system's complexity due to more steps and schemes to classify the users within the MIMO system.

The proposed water-filling $P F$ scheme achieves throughput gain for cell-edge users that farther from the BS at the expense of throughput loss of users closer to the BS. On the other hand, the algorithm in [8] achieves better system throughput using the joint detection scheme that enables the farther user to jointly detect the nearer user's under-laid signal. Simultaneously, the interference in the proposed scheme is reduced by the joint demodulation. The proposed scheme in [9] experiences higher computational complexity because of the difficulties to calculate the channel gains for the Single user SU-MIMO.

The co-channel user set selection proposed in [10] considering the distributed power among the multiplexed users shared on each sub band to maximize the weighted sum rate. Since the problem is a non-convex combinational optimization, the scheme employs two- steps of heuristic algorithm. The difference of convex (DC) is adopted in the first step. Then the second step uses the same iterative PA algorithm. The work achieves a better performance of the greedy user selection compared to an exhaustive user selection scheme.

As well as a better performance of the power distribution among users and subcarriers based on the iterative DC algorithm compared to empirical FTPA schemes [10] . Furthermore, the DC programming approach achieved a high mean system throughput by using power distribution among the sub bands at the cost of the more system complexity and control channel overhead [10].

In [2], the authors discuss the performance of the NOMA-based system under various wireless network techniques such as MIMO, beamforming, space-time coding, cooperative communication and network coding among users or networks. The resource allocation problem in NOMA is mathematically formulated, and its tractability is characterized and analyzed under considerations of the users' channel gains, total power budget, the individual power limit and the maximum number of multiplexed users on each subcarrier in this work [11].

Moreover, an algorithm framework of a combination of Lagrangian duality and dynamic programming (LDDP) proposed to achieve near-optimal solutions and the NP-hardness also proven in [11]. The proposed algorithm has shown a significant improvement of the system throughput performance compared to the conventional OMA as well as the previous resource allocation schemes in NOMA systems [11].

The work in [12] and [13] propose resource allocation for multi-carrier NOMA system to improve the system weighted throughput and MC-NOMA system performance, respectively. A near-optimal performance is achieved through the suboptimal algorithm while a substantial system throughput improvement is provided by the proposed resource allocation algorithm using monotonic optimization for MC-NOMA in comparison to the conventional multi-carrier orthogonal multiple access (MC-OMA) [12]. The work in [13] considers a three steps algorithm which applies the synchronous iterative water-filling algorithm (SIWA) twice followed by Double Iterative Water-Filling Algorithm (DIWA) method. The DIWA performance shows much lower time complexity compared to the existing near-optimal solutions [13]. Based on the proposed schemes in [13], the sum rate maximization is achieved with less computational time.

The work in [14] focuses on the of cell-edge users' throughput by adopting orthogonal signaling with water filling scheme (NOMA-OS-WF), NOMA with water filling (NOMA-WF), orthogonal signaling with water filling (OS-WF), NOMA and orthogonal signaling with equal power (NOMA-OS-EQ). In general, the NOMA system always outperforms as much as $20 \%$ higher than orthogonal signaling (OS) and the NOMA-OS-WF shows better performance than NOMA-WF [14].

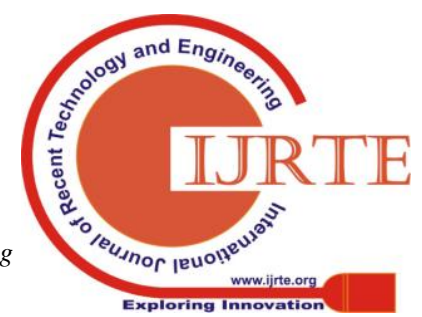


The water filling-based PA shows a better performance than the equal power allocation (EPA) in term of a higher number of cell-edge users while considering a limited number of users in the cell [14].

The scheme in [15] proposed a matching algorithm to perform access points (APs) association and resource allocation that achieves a higher system throughput than the other schemes. Thus, the increment of the number of users and APs in the system can offer system's throughput improvement. The system throughput is improved using matching algorithm, which can limit interference if the APs are associated systematically rather than randomly. These considerations can offer the APs association as an optimal scheme for multi-user. The proposed scheme applied NOMA techniques to enable the system to associate multiple APs on the same radio blocks (RBs) that obtains a significant gain. Moreover, the PA based on DC programming shows a better performance, which enable the NOMA techniques in the ultra-dense network (UDN) effectively [15].

Hungarian algorithm is suggested in [6] to maximize the overall throughput of NOMA system. The proposed algorithm is used to perform the optimal power control, user scheduling, and resource allocation. The enhancement of the overall throughput is achieved due to using user scheduling and user pairing that can effectively reduce the complexity of the PA schemes in case of multicarrier NOMA system. The user pairing algorithm in [6] creates a substantial improvement of the system throughput especially for a system with a large diversity in users' channel gain.

\section{PERFORMANCE ANALYSIS}

This section selects a few popular PA schemes in NOMA system for comparison in terms of throughput. Fig. 3 depicts a comparison between the algorithms of water-filling (WF) -PF proposed in [9] and NOMA-OSWF proposed in [14] in which both schemes aim to achieve high user throughput in the power domain. The proposed scheme in [9] shows that WF-PF is able to achieve the average user's throughput but greatest loss is observed for the users closer to the BS.

The authors in [14] focus on radio resources employment in power domain such as OS and WF by combining NOMA and OS-WF to improve the cell-edge user throughput. The WF-based PA shows a better performance than the equal power allocation in term of a higher throughput for cell edge user regardless of cell's user fairness while considering a limited number of users in the cell according to [14]. As observed in [14], the NOMA-OS-WF shows a better performance for the user's throughput in NOMA-based system due to the combination of water-filling, orthogonal signaling and NOMA schemes that deliberated over the computational complexity.

According to Fig. 4 , the NOMA-OS-WF scheme shows a better performance in terms of throughput due to higher capability and flexibility to adopt a large number of users in the cell. In contrast, when the number of users increased, the average rate loss for the closer user to $\mathrm{BS}$ and average rate gain for the farther user BS is decreased for the WF-PF algorithm in [9] .

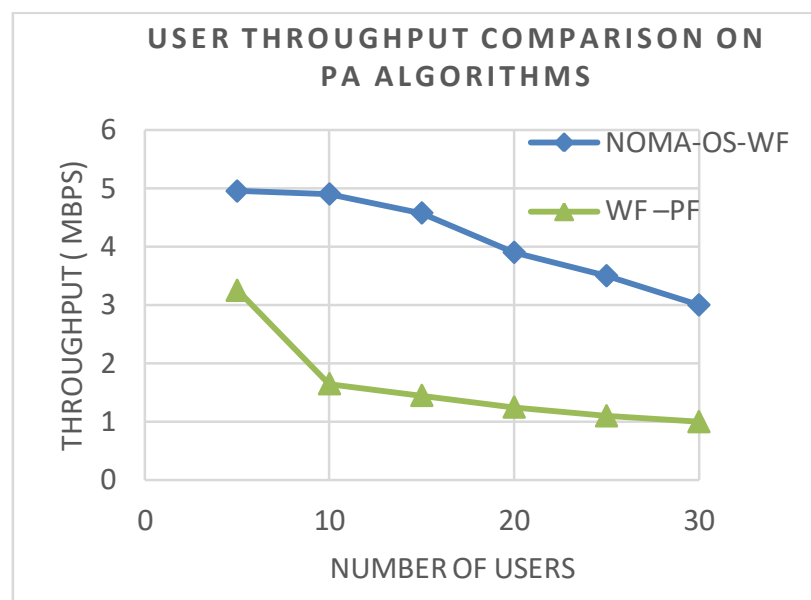

Fig. 5 Achieved user Throughput comparison between [9] and [14].

Fig. 6 depicts the increment of the geometric mean of the user throughput when three users are multiplexed per subcarrier using a genetic algorithm (GA) approach with using an optimized power level [16]. In addition, the proposed scheme executes a random user grouping in NOMA system. Thus, the more users are allowed to share the same subcarrier to enhance the chances to cancel the interference.

Although, the GA approach shows a better throughput performance when three users are multiplexed rather than two users due to the optimized power levels among three users, which can offer more chances to cancel the interference. In term of complexity, the more multiplexed users may not offer a flexible system due to difficulties to cancel interference in the system with more than three multiplexed users.

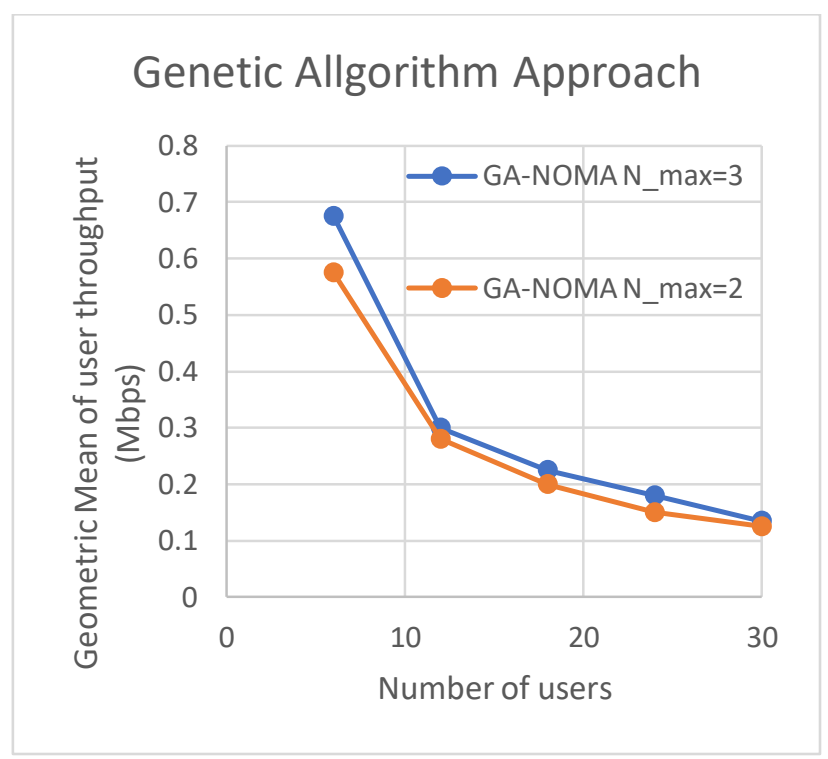

Fig. 7 Genetic Algorithm approach comparison between numbers of multiplexed users [16].

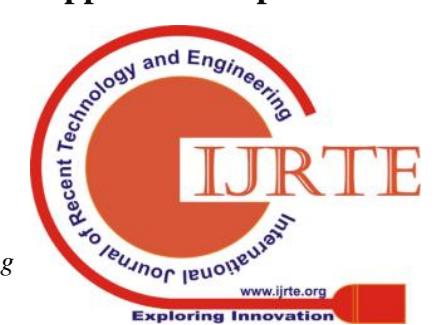




\section{CONCLUSION}

The study provides a comprehensive overview of the throughput performance in power allocation schemes to maximize the throughput of NOMA-based 5G networks. It explains the concept of the NOMA-based system and provides an instance on throughput calculation. The study also discusses the problem formulation of power allocation in terms of the employed algorithms, objective functions, constraints, problem limits and considerations.
In addition, the paper demonstrates a comparison on the existing water filling algorithms and the revised algorithms in terms of throughput performance, time efficiency and computational complexity. Ultimately, the channel condition is a major indicator to apply the power allocation. Strategies to enhance the network performance might involve the number of multiplexed users on the same subcarrier. There would therefore seem to be a definite need for any algorithm in NOMA system to take into account the user on the edge of the cell and the close to the BS.

APPENDIX

Table 1 Power Allocation Schemes for NOMA-based system 5G networks

\begin{tabular}{|c|c|c|c|c|}
\hline Rf. & Constraints & Algorithm & $\begin{array}{l}\text { Considerations } \\
\text { \&Limits }\end{array}$ & Objective Function \\
\hline [15] & $\begin{array}{l}\text {-Max. Transmit power. } \\
\text {-Required data rate. }\end{array}$ & $\begin{array}{l}\text {-Matching Algorithm. } \\
\text {-DC programming. }\end{array}$ & $\begin{array}{l}\text {-CSI. } \\
\text {-Aps associations. } \\
\text {-Iterations }\end{array}$ & $\begin{array}{l}\text {-Achievable Data Rate. } \\
\text {-Maximum Throughput }\end{array}$ \\
\hline [8] & $\begin{array}{l}\text {-Transmit power } \\
\text { between near and far } \\
\text { user. }\end{array}$ & $\begin{array}{l}\text {-Proportional Fairness (PF) } \\
\text { Scheduler. } \\
\text {-Joint detection scheme. }\end{array}$ & $\begin{array}{l}\text {-Multi-cell. } \\
\text { User pairing. }\end{array}$ & $\begin{array}{l}\text {-Maximize both Throughput } \\
\text { and User fairness. }\end{array}$ \\
\hline [9] & $\begin{array}{l}\text {-Total power and } \\
\text { waterline of Power } \\
\text { Allocation. }\end{array}$ & $\begin{array}{l}\text { - Proportional Fairness (PF) } \\
\text { scheduler. } \\
\text {-Joint iterative water-filling } \\
\text { based FTPA. }\end{array}$ & $\begin{array}{l}\text {-Channel Gain } \\
\text {-SU -MIMO } \\
\text {-Tested users }\end{array}$ & $\begin{array}{l}\text { - Maximizing both } \\
\text { Throughput and Users } \\
\text { Fairness. }\end{array}$ \\
\hline [17] & $\begin{array}{l}\text {-The transmission. } \\
\text {-The traffic models. }\end{array}$ & $\begin{array}{l}\text {-Realistic file transfer } \\
\text { protocol (FTP) traffic model. }\end{array}$ & $\begin{array}{l}\text {-SIC } \\
\text {-QoE at the cell } \\
\text { edge. }\end{array}$ & $\begin{array}{l}\text {-Enhance the system } \\
\text { throughput. } \\
\text {-Weighted PF }\end{array}$ \\
\hline [7] & $\begin{array}{l}\text {-Transmission power } \\
\text { allocation coefficient. }\end{array}$ & $\begin{array}{l}\text {-Stochastic geometry and } \\
\text { queueing theory. }\end{array}$ & $\begin{array}{l}\text { - (CSI) at BS. } \\
\text {-Queue length }\end{array}$ & $\begin{array}{l}\text {-Enhance the stable } \\
\text { Throughput region. }\end{array}$ \\
\hline [14] & $\begin{array}{l}\text {-Remain power between } \\
\text { sub-bands. } \\
\text {-Maximum transmit } \\
\text { power for Min number } \\
\text { of Sub-bands. }\end{array}$ & $\begin{array}{l}\text {-Water-filling. } \\
\text {-Adaptive switching to } \\
\text { orthogonal signaling (OS). }\end{array}$ & $\begin{array}{l}\text {-The channel gains. } \\
\text {-No. Users/Cell. }\end{array}$ & $\begin{array}{l}\text {-Maximizing system } \\
\text { throughput. } \\
\text {-Minimizing bandwidth. } \\
\text {-Maximize SE. }\end{array}$ \\
\hline [16] & -Transmit Power. & $\begin{array}{l}\text {-Genetic algorithm (GA). } \\
\text { - Iterative gradient ascend } \\
\text { method (IGAM). }\end{array}$ & - OFDM- NOMA & $\begin{array}{l}\text {-Maximize Geometric mean } \\
\text { of user throughputs. }\end{array}$ \\
\hline [12] & $\begin{array}{l}\text { - Maximum transmit } \\
\text { power allowance. } \\
\text {-2users/Each subcarrier } \\
\text {-The non-negative } \\
\text { transmit power. }\end{array}$ & $\begin{array}{l}\text {-Monotonic Optimization. } \\
\text { - Outer Polyblock } \\
\text { Approximation Algorithm. } \\
\text { - Projection Algorithm. } \\
\text { - Successive Convex } \\
\text { Approximation. }\end{array}$ & -MCNOMA. & $\begin{array}{l}\text {-Maximize the weighted } \\
\text { system throughput. }\end{array}$ \\
\hline [18] & $\begin{array}{l}\text {-Powers of the users on } \\
\text { each channel. } \\
\text { - (QoS) and Weights. }\end{array}$ & $\begin{array}{l}\text {-Iterative matching } \\
\text { algorithm. }\end{array}$ & $\begin{array}{l}\text {-SIC } \\
\text {-stability }\end{array}$ & $\begin{array}{l}\text { Maximize Fairness, } \\
\text { Weighted Sum rate and } \\
\text { Energy Efficiency. }\end{array}$ \\
\hline [5] & $\begin{array}{l}\text { - } \alpha \text {-fairness. } \\
\text { - Equivalent power for } \\
\text { user. }\end{array}$ & $\begin{array}{l}\text { - Simple alternate } \\
\text { optimization (AO) algorithm. } \\
-\alpha \text {-fairness model. }\end{array}$ & $\begin{array}{l}\text {-Statistical \& } \\
\text { Perfect (CSIT). }\end{array}$ & $\begin{array}{l}\text {-Maximize both } \\
\text { instantaneous sum rate and } \\
\text { sum throughput. }\end{array}$ \\
\hline [10] & -Total transmit power. & $\begin{array}{l}\text {-Iterative DC. } \\
\text { - Superposition Coding (SC). } \\
\text { - Greedy User Selection } \\
\text { Algorithm. }\end{array}$ & $\begin{array}{l}\text { - complete (CSI). } \\
\text { Allowable time. }\end{array}$ & $\begin{array}{l}\text {-Maximize both the system } \\
\text { weighted sum rate and } \\
\text { Throughput. }\end{array}$ \\
\hline [11] & $\begin{array}{l}\text {-Total power budget. } \\
\text {-Maximum number of } \\
\text { multiplexed users on } \\
\text { each subcarrier. }\end{array}$ & $\begin{array}{l}\text { Lagrangian duality and } \\
\text { dynamic programming } \\
\text { (LDDP). } \\
\text {-Lagrangian Duality and } \\
\text { Power Discretization }\end{array}$ & $\begin{array}{l}\text {-Required power. } \\
\text {-No. users/ } \\
\text { subcarrier. }\end{array}$ & $\begin{array}{l}\text {-Maximize both throughput } \\
\text { and fairness. }\end{array}$ \\
\hline & $\begin{array}{l}\text { Number: C10191083S19/20 } \\
\text { 5940/ijrte.C1019.1083S19 }\end{array}$ & 105 & $\begin{array}{l}\text { Published By: } \\
\text { Blue Eyes Intelligence En } \\
\& \text { Sciences Publication }\end{array}$ & \\
\hline
\end{tabular}




\begin{tabular}{|c|c|c|c|c|}
\hline & & (LDPD) & & \\
\hline [6] & $\begin{array}{l}\text {-Outage probability } \\
\text { threshold, } \\
\text {-Maximum transmit } \\
\text { power on each channel. } \\
\text {-Minimum bandwidth } \\
\text { allocated to pairing } \\
\text { users. }\end{array}$ & $\begin{array}{l}\text { - Hungarian algorithm. } \\
\text { - Closed-form optimal power } \\
\text { control. }\end{array}$ & $\begin{array}{l}\text { - Perfect \& } \\
\text { imperfect (CSI). } \\
\text {-Distance }\end{array}$ & $\begin{array}{l}\text {-Maximize both overall } \\
\text { network throughput and User } \\
\text { fairness. }\end{array}$ \\
\hline [19] & $\begin{array}{l}\text {-Transmit power } \\
\text { allocated to sub-band. }\end{array}$ & $\begin{array}{l}\text { Proportional Fairness (PF) } \\
\text { scheduler. } \\
\text { Joint iterative water-filling } \\
\text { based PA. }\end{array}$ & $\begin{array}{l}\text { Channel gain. } \\
\text { No. sub bands. }\end{array}$ & $\begin{array}{l}\text {-Maximizing the achieved } \\
\text { average throughput. }\end{array}$ \\
\hline [20] & $\begin{array}{l}\text {-Maximum transmit } \\
\text { power at BS. } \\
\text {-The energy harvesting } \\
\text { at the users, } \\
\text { - The time. }\end{array}$ & $\begin{array}{l}\text {-Wireless power transfer } \\
\text { (WPT) technique. }\end{array}$ & $\begin{array}{l}\text {-Multiple Antenna } \\
\text { at base station. } \\
\text { - (CSIs). }\end{array}$ & $\begin{array}{l}\text {-Optimizing Throughput\& } \\
\text { energy beamforming at BS. }\end{array}$ \\
\hline$[21]$ & $\begin{array}{l}\text {-Maximum transmit } \\
\text { power. } \\
\text { - SU and PU } \\
\text { interference. }\end{array}$ & $\begin{array}{l}\text {-Matrix operations. } \\
\text {-Iterative PA algorithm. } \\
\text {-Baseline PA Algorithm- } \\
\text { FTPC. }\end{array}$ & $\begin{array}{l}\text { - QOS. } \\
\text {-SINR. } \\
\text {-NOMA OFDM }\end{array}$ & - Improve performance. \\
\hline [22] & $\begin{array}{l}\text { - Average and peak } \\
\text { power. } \\
\text { - Minimum average user } \\
\text { rate. } \\
\text { - Maximum allowable } \\
\text { user outage. }\end{array}$ & $\begin{array}{l}\text { - Lagrangian dual } \\
\text { decomposition (LDD). }\end{array}$ & $\begin{array}{l}\text {-Full \& Partial } \\
\text { CSIT. } \\
\text { Delay transmission. }\end{array}$ & $\begin{array}{l}\text {-Maximize both average } \\
\text { sum-rate and sum of delay- } \\
\text { limited throughput (DLT). }\end{array}$ \\
\hline [23] & $\begin{array}{l}\text {-Quality of Service } \\
\text { (QoS). } \\
\text {-Power allocation. } \\
\text {-Binary variables for cell } \\
\text { selection. }\end{array}$ & $\begin{array}{l}\text {-Outer approximation } \\
\text { approach (OAA) based on } \\
\text { linear programming }\end{array}$ & Multi-cell & $\begin{array}{l}\text { - Maximize overall } \\
\text { throughput of network }\end{array}$ \\
\hline [13] & $\begin{array}{l}\text {-Maximum transmit } \\
\text { power. } \\
\text {-Maximum multiplexed } \\
\text { users per subcarrier. }\end{array}$ & $\begin{array}{l}\text {-Synchronous iterative water } \\
\text { filling algorithm (SIWA). } \\
\text { - A heuristic greedy } \\
\text { Method. } \\
\text { - Double Iterative Water } \\
\text { Filling Algorithm (DIWA). } \\
\text { - Iterative water filling } \\
\text { algorithm (IWA). }\end{array}$ & $\begin{array}{l}\text {-Convergence time } \\
\text { of SIWA. }\end{array}$ & $\begin{array}{l}\text { - Maximize the sum of data } \\
\text { rates. }\end{array}$ \\
\hline
\end{tabular}

[4] Benjebbour, A., Saito, Y., Kishiyama, Y., Li, A., Harada, A., \& Nakamura, T. (2013, November).

\section{REFERENCE}

[1] Ding, Z., Liu, Y., Choi, J., Sun, Q., Elkashlan, M., \& Poor, H. V. (2015). "Application of nonorthogonal multiple access in LTE and $5 \mathrm{G}$ networks." arXiv preprint arXiv:1511.08610.

[2] Islam, S. R., Avazov, N., Dobre, O. A., \& Kwak, K. S. (2016). "Power-domain non-orthogonal multiple access (NOMA) in 5G systems: Potentials and challenges." IEEE Communications Surveys \& Tutorials, 19(2), 721-742.

[3] Al-Abbasi, Z. Q., \& So, D. K. (2015, August). "Power allocation for sum rate maximization in non-orthogonal multiple access system." In 2015 IEEE 26th Annual International Symposium on Personal, Indoor, and Mobile Radio Communications (PIMRC) (pp. 1649-1653). IEEE.

"Concept and practical considerations of nonorthogonal multiple access (NOMA) for future radio access." In 2013 International Symposium on Intelligent Signal Processing and Communication Systems(pp. 770-774). IEEE.

[5] Xu, P., \& Cumanan, K. (2017). "Optimal Power Allocation Scheme for Non-Orthogonal Multiple Access With alpha Fairness." IEEE Journal on Selected Areas in Communications, 35(10), 23572369.

[6] Zhang, Z., Xia, Q., Yu, G., \& Liu, R. (2017, October). " Power control, user scheduling and resource Allocation for Downlink NOMA Systems with Imperfect Channel State Information." In 2017 9th International Conference on Wireless Communications and Signal Processing $(W C S P)($ pp. 1-6). IEEE. 
[7] Zhou, Y., \& Wong, V. W. (2017, May). "Stable throughput region of downlink NOMA transmissions with limited CSI." In 2017 IEEE International Conference on Communications (ICC) (pp. 1-7). IEEE.

[8] Yazaki, T., \& Sanada, Y. (2015, November). "Throughput performance of non-orthogonal multple access with joint detection in far user." In 2015 International Symposium on Intelligent Signal Processing and Communication Systems (ISPACS) (pp. 537-541). IEEE.

[9] Youssef, M. J., Farah, J., Nour, C. A., \& Douillard, C. (2017, July). "Waterfilling-based resource allocation techniques in downlink Non-Orthogonal Multiple Access (NOMA) with Single-User MIMO." In 2017 IEEE Symposium on Computers and Communications (ISCC) (pp. 499-506). IEEE.

[10] Parida, P., \& Das, S. S. (2014, December). "Power allocation in OFDM based NOMA systems: A DC programming approach." In 2014 IEEE Globecom Workshops (GC Wkshps) (pp. 1026-1031). IEEE.

[11] Lei, L., Yuan, D., Ho, C. K., \& Sun, S. (2016). " Power and channel allocation for non-orthogonal multiple access in 5G systems: Tractability and computation." IEEE Transactions on Wireless Communications, 15(12), 8580-8594.

[12] Sun, Y., Ng, D. W. K., Ding, Z., \& Schober, R. (2016, December)." Optimal joint power and subcarrier allocation for MC-NOMA systems." In 2016 IEEE Global Communications Conference (GLOBECOM) (pp. 1-6). IEEE.

[13] Fu, Y., Salaün, L., Sung, C. W., Chen, C. S., \& Coupechoux, M. (2017, May). "Double iterative waterfilling for sum rate maximization in multicarrier NOMA systems." In 2017 IEEE International Conference on Communications (ICC) (pp. 1-6). IEEE.

[14] Hojeij, M. R., Farah, J., Nour, C. A., \& Douillard, C. (2015, May)." Resource allocation in downlink non-orthogonal multiple access (NOMA) for future radio access." In 2015 IEEE 81st vehicular technology conference (VTC Spring) (pp. 1-6). IEEE.

[15] Liu, Y., Li, X., Ji, H., \& Zhang, H. (2017, May). "A multi-user access scheme for throughput enhancement in UDN with NOMA." In 2017 IEEE International Conference on Communications Workshops (ICC Workshops) (pp. 1364-1369). IEEE.

[16] Gemici, Ö. F., Kara, F., Hokelek, I., Kurt, G. K., \& Çırpan, H. A. (2017, July). "Resource allocation for NOMA downlink systems: Genetic algorithm approach. " In 2017 40th International Conference on Telecommunications and Signal Processing (TSP) (pp. 114-118). IEEE.

[17] Kimura, M., \& Higuchi, K. (2015, August) "System-level throughput of NOMA with SIC in cellular downlink under FTP traffic model. " In 2015 International Symposium on Wireless Communication Systems (ISWCS) (pp. 1-5). IEEE.

[18] Zhu, J., Wang, J., Huang, Y., He, S., You, X., \& Yang, L. (2017). " On optimal power allocation for downlink non-orthogonal multiple access systems. "IEEE Journal on Selected Areas in Communications, 35(12), 2744-2757.

[19] Hojeij, M. R., Nour, C. A., Farah, J., \& Douillard, C. (2017). " Waterfilling-based proportional fairness scheduler for downlink non-orthogonal multiple access." IEEE Wireless Communications Letters, 6(2), 230-233.

[20] Pang, H., Zhang, G., Wu, Q., \& Cui, M. (2017, December). " Throughput maximization for wireless powered non-orthogonal multiple access networks with multiple antennas." In 2017 23rd Asia-Pacific Conference on Communications $(A P C C)$ (pp. 1-5). IEEE.

[21] Zeng, M., Tsiropoulos, G. I., Dobre, O. A., \& Ahmed, M. H. (2016, December). " Power allocation for cognitive radio networks employing non-orthogonal multiple access." In 2016 IEEE Global Communications Conference (GLOBECOM) (pp. 1-5). IEEE.

[22] Xing, H., Liu, Y., Nallanathan, A., Ding, Z., \& Poor, H. V. (2018). "Optimal throughput fairness tradeoffs for downlink non-orthogonal multiple access over fading channels." IEEE Transactions on Wireless Communications, 17(6), 3556-3571.

[23] Ali, M., Rabbani, Q., Naeem, M., Qaisar, S., \& Qamar, F. (2017). "Joint user association, power allocation, and throughput maximization in $5 \mathrm{G} \mathrm{H}-$ CRAN networks." IEEE Transactions on Vehicular Technology, 66(10), 9254-9262. 


\section{AUTHORS PROFILE}

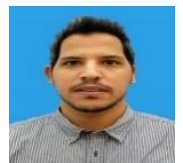

OSAMA M.S. ABUAJWA is a $\mathrm{PhD}$ candidate in Wireless communication networks at Faculty of Engineering at Multimedia University. His research interest is in Heterogeneous networks, Networks QoS, 5G networks, and Optimization Techniques. His other research include Power Allocation techniques in Non-Orthogonal Multiple Access schemes in 5G network. He received the B.Eng. degree (with honors) in Electronics Engineering (Honors) Major in Telecommunications, Multimedia University, Malaysia, in 2015. His M.Sc. degree Master's Degree in Electronics (Communication and Computer Engineering) Nottingham University Malaysia, in 2016.

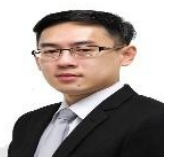

Tan Chee Keong holds the degrees of B.Eng (Electronics majoring in Telecommunication), M.Eng.Sc (wireless communications) and Ph.D (wireless communications) from Multimedia University, Malaysia. Currently, he serves as a senior lecturer in Faculty of Engineering, Multimedia University, Malaysia. As the lecturer in Multimedia University, Dr. Tan has involved in lecture for many undergraduate and postgraduate courses such as data communications and computer networking, analog and digital communications, mobile and satellite communications, communication networks, etc. Dr. Tan is an telecommunication engineering expert and consultant with over 10 years of experience in telecommunication research, lectures and practice. He is also an experienced speaker and teacher, having taught many highly-rated university level courses, industry short courses, tutorials at conferences, to a wide range of students from industry, academia and government. Specializing in wireless system design, Dr. Tan has carried out projects for telecommunication companies and cellular service providers which led to the development of two patents on wireless algorithm and protocol design. Furthermore, he is the main contributing authors to more than 10 international journal papers, particularly on the radio resource management for various wireless systems. His current research interests include radio resource management, software-defined network, 5G networks, indoor positioning scheme, machine learning, artificial intelligence, data science, and etc.

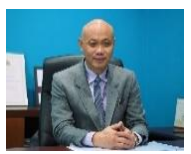

Ching Kwang Lee received his B.Sc. in Communication Engineering and $\mathrm{PhD}$ degrees in microwave antennas from the University of Kent at Canterbury (UKC), United Kingdom, in 1982 and 1987 respectively. He was a research fellow in microwave antenna, majoring in frequency selective surface, at the above university between 1988 and 1990. He then joined the ElectroOptic Group, Division of Radio physics (Now renamed as Telecommunications and Industrial Physics since Sept 1996) at Commonwealth Scientific Industrial Research Organization (CSIRO), in Australia as a research scientist from October 1990 to July 1991 working on near field range.

He began my career in academia as a faculty member of the School of Electrical and Electronic Engineering, Nanyang Technological University, Singapore from 1991 to 2010. Subsequently joined Faculty of Engineering at Multimedia University, Malaysia since Nov 2010, with an additional portfolio as Director of Graduate Institute of Engineering from March 2014 to July201 and the dean from Aug2018 to Feb2019. His research interests include frequency-selective surfaces, optimization algorithm, antenna analysis, mess networking, optical networking and software-defined network. He has been a Chartered Engineer from Institution of Engineering and Technology (IET) since 1991 and elected as a Fellow in 2017. A senior member of Institute of Electrical and Electronics Engineers (IEEE). In December 2016. 